\title{
MMPI Profile of Individuals with Migraine
}

\author{
Shivani, Vinod K Sinha ${ }^{1}$, Bharati Roy ${ }^{2}$ \\ Department of Clinical Psychology, Central Institute of Psychiatry, Ranchi, ${ }^{1}$ Department of \\ Psychiatry, Central Institute of Psychiatry, Ranchi, ${ }^{2}$ Department of Psychology, Ranchi University, \\ Ranchi
}

\section{ABSTRACT}

Introduction : Migraine is a neurological syndrome characterized by altered bodily perceptions, severe headaches, and nausea, more common to women than to men. Various psychiatric disorders like panic disorder and depression have been associated with migraine, leading to further disability of migraine sufferers in all aspects of their daily lives. The aim of study was to assess the personality pattern of individuals with migraine as compared to normal. Method : Individuals, both normal controls and migraine sufferers were assessed on Minnesota Multiphasic Personality Inventory (MMPI-2). Result : Elevations were found in the scales on hypochondriasis, depression, hysteria, psychasthenia and schizophrenia. Females were more to have reported headaches. Individuals with migraine showed lower level of education along with positive family history. Conclusion : Migraine sufferers display a conversion profile with depression being common. Although some psychotic scales may be elevated but they do not qualify for an independent identity.

Keywords : Migraine, psychopathology, conversion profile, psychotic scales, MMPI-2.

\section{INRODUCTION}

Migraine is characterized by episodes of headache that is often throbbing and frequently unilateral and may be severe. It can cause difficulty with work and life; frequently, if not diagnosed or treated appropriately. In migraine without aura (previously known as common migraine), attacks are usually associated with nausea, vomiting, or sensitivity to light, sound, or movement. When untreated, these

\section{Corresponding Author}

Ms Shivani, PhD Scholar (Clinical Psychology),

Central Institute of Psychiatry, Ranchi

E. mail : kunwar.shivani@gmail.com attacks typically last 4 to 72 hours. A combination of features is required for the diagnosis, but not all features are present in every attack or in every patient (Olesen et al. 2000). Approximately one-third of people who suffer migraine headache perceive an aura-unusual visual, olfactory, or other sensory experiences that are a sign that the migraine will soon occur.

Psychopathological problems are prominent among patients with severe headache. In headache patients the most frequent psychiatric conditions are anxiety and mood disorders (Guidetti \& Galli, 2002). Psychiatric comorbidity plays a role in prolonging and making the course of headache enduring. The association between headache and depression or anxiety has been well documented for years (Merikangas et al., 1990). 


\section{Shivani, et al.: MMPI Profile of Individuals with Migraine}

Previous studies have shown that subjects with anxiety and a combination of anxiety disorders and major depression are more likely to be affected by migraine (Zwart et al., 2003) and that the cooccurrence of psychiatric disorders in women with migraine appears to be influential on history of headachein thelong term. Yetanother work(Mongini et al., 1997) in which the Minnesota Multiphasic Personality Inventory (MMPI-2) was administered on patients with chronic daily headache (CDH), an elevation of several MMPI scales and a fairly large number of psychosomatic symptoms were found in almost all patients. The role of psychological factors in the development of chronic headache needs to be elucidated; hence the aim of our study is to assess the personality pattern of individuals with migraine using the MMPI-2.

\section{METHOD}

Subjects selected with frequent headache attacks seen from March 2011 to November 2011 at a tertiary care center for headache were based on :

1. Individuals diagnosed with migraine according to the diagnostic criteria for migraine with/ without aura of the International Classification of Headache Disorders (ICHD II, 2004).

2. Primary school education with ages between 16 and 60 years.

3. Absence of any major psychiatric disorder, medical disorder causing headache (such as sinusitis, neck trauma) or neurological disorder (trigeminal neuralgia, non-vascular intracranial disorder).

4. Absence of Past history of significant head injury or drug/alcohol use in past 6 months.

5. Giving informed consent.

All the subjects were divided in two groups-

a) Group 1= Experimental group (migraine patients)

b) Group 2= Control group (normal subjects)
All individuals hadtheir personality and psychopathology assessed by the MMPI-2 (Butcher et al., 1989), under the supervision of a psychologist. Normal controls were selected if they scored less than 3 on the general health questionnaire (GHQ 12) (Goldberg \& William, 1988), which is a 12 item scale assessing the general health of individuals. Only subjects who met the above mentioned inclusion and exclusion criterion were made a part of this study. The MMPI-2 is a 567-item, true-false questionnaire that evaluates personality on 8 validity and 10 clinical scales. For each scale, a T-score of 65 is considered to be the level of clinical significance in the 95th percentile.

A minimum of 35 migraine sufferers and 35 normal subjects were selected in total for the assessment. The number of drop outs was more in headache patients (5) as compared to normal controls (3) considering the length of the test being administered. There were 3 invalid MMPI profiles in both the groups because of inconsistent responding, hence only the valid profiles of the patients were interpreted and analyzed.

Descriptive statistics and chi-square test were used for comparison of the socio-demographic variables like gender, occupation, education, age, religion and socio-economic status.t-test was applied for the comparison of the validity and clinical scales between the experimental and control group. The occurrences of T-scores $>65$ were analyzed using Fischer's two-sided exact test, the odds ratio being calculated considering a 95\% confidence interval. The $\mathrm{p}$ values are presented at 0.05 level assuming the equal variance.

\section{RESULT}

A total of 27 migraine patients and 29 normal controls were assessed and analyzed. There was no significant difference in the gender, occupation, religion or socio economic status among the groups, though females being more in number. A significant difference was seen in the variables education and family history. Migraine sufferers seemed to be having lower education $(\mathrm{p}<.001)$ with a positive family history $(\mathrm{p}<.05)$, displayed in table 1 . 
Shivani, et al.: MMPI Profile of Individuals with Migraine

Table-1 : Socio-demographic characteristics $(\mathrm{N}=56)$

\begin{tabular}{|c|c|c|c|c|c|c|}
\hline & & $\begin{array}{c}\text { Experimental } \\
\quad(n=27)\end{array}$ & $\begin{array}{c}\text { Control } \\
(n=29)\end{array}$ & $\chi^{2}$ & df & p \\
\hline \multirow[t]{2}{*}{ Gender } & Male & $10(37.0)$ & $7(24.1)$ & 1.100 & 1 & 0.224 \\
\hline & Female & $17(63.0)$ & $22(75.9)$ & & & \\
\hline \multirow[t]{5}{*}{ Education } & $\begin{array}{l}\text { Primary and } \\
\text { Secondary }\end{array}$ & $11(40.7)$ & $2(6.9)$ & 15.437 & 3 & $.001^{* *}$ \\
\hline & $\begin{array}{l}\text { Higher } \\
\text { secondary }\end{array}$ & $8(29.7)$ & $23(79.3)$ & & & \\
\hline & Graduation & $6(22.2)$ & $2(6.9)$ & & & \\
\hline & Post & $2(7.4)$ & $2(6.9)$ & & & \\
\hline & Graduation & & & & & \\
\hline \multirow[t]{2}{*}{ Occupation } & Employed & $12(44.4)$ & 8 (27.6) & 1.731 & 1 & 0.150 \\
\hline & Unemployed & $15(55.6)$ & $21(72.4)$ & & & \\
\hline \multirow{2}{*}{$\begin{array}{l}\text { Family } \\
\text { history }\end{array}$} & Significant & 15 (55.6) & 8 (27.6) & 4.51 & 1 & $.031^{*}$ \\
\hline & $\begin{array}{l}\text { Non- } \\
\text { Significant }\end{array}$ & $12(44.4)$ & $21(72.4)$ & & & \\
\hline \multirow[t]{2}{*}{ Religion } & Hindu & $15(55.6)$ & $10(34.5)$ & 2.512 & 1 & .094 \\
\hline & Other & $12(44.4)$ & $19(65.5)$ & & & \\
\hline \multirow[t]{3}{*}{ SES } & Lower & $9(33.4)$ & $8(27.6)$ & 2.401 & 2 & .301 \\
\hline & Middle & $13(48.1)$ & $19(65.5)$ & & & \\
\hline & Upper & $5(18.5)$ & $2(6.9)$ & & & \\
\hline
\end{tabular}

$\mathrm{p}<.05^{*}, \mathrm{p}<.01^{* *}$ 


\section{Shivani, et al.: MMPI Profile of Individuals with Migraine}

No significant difference was apparent as far as the validity scales were concerned except for the higher mean ages in group 1(33) in comparison with group 2 (24), which turned out to be $\mathrm{p}<.001$, presented in table 2. As regards the psychological evaluation of the clinical scales (Table 3), the mean MMPI-2 scores were consistently higher in group 1 than in group 2 , with significant differences for hypochondriasis
(Hs) : P <.001; depression (D) : $\mathrm{P}<.001$; hysteria (Hy) : $\mathrm{P}<.001$; psychasthenia $(\mathrm{Pt}) \mathrm{p}<.05$; schizophrenia (Sc) : $\mathrm{P}<.05$; psychopathic deviate (Pd) $\mathrm{P}<.001$ and paranoia ( $\mathrm{Pa}) \mathrm{P}<.001$. The mean duration of illness was found to be 38 months, the skewness occurred probably because of the varied duration of illness ranging from few months to more than ten years.

Table 2 : Evaluation of individuals on age and validity scales $(\mathrm{N}=56)$

\begin{tabular}{|c|c|c|c|c|c|}
\hline \multicolumn{6}{|c|}{ Mean \pm SD } \\
\hline & $\begin{array}{c}\text { Experimental } \\
\quad(n=27)\end{array}$ & Control $(n=29)$ & $t$ & df & $\mathbf{P}$ \\
\hline Age & $33.89 \pm 11.748$ & $24.48 \pm 8.283$ & -3.482 & 54 & $.001^{* *}$ \\
\hline $\begin{array}{l}\text { Illness duration } \\
\text { (months) }\end{array}$ & $38.00 \pm 34.745$ & - & -5.894 & 54 & .000 \\
\hline Can't say & $3.30 \pm 4.36$ & $1.76 \pm 2.340$ & -1.659 & 54 & .103 \\
\hline VRIN & $67.0 \pm 8.68$ & $68.59 \pm 7.863$ & .483 & 54 & .631 \\
\hline TRIN & $63.67 \pm 8.549$ & $63.93 \pm 8.341$ & .117 & 54 & .907 \\
\hline $\mathbf{F}$ & $71.41 \pm 11.281$ & $66.79 \pm 10.561$ & -1.581 & 54 & .120 \\
\hline FB & $70.26 \pm 10.365$ & $71.23 \pm 9.659$ & .536 & 54 & .560 \\
\hline Fp & $71.19 \pm 10.134$ & $71.07 \pm 6.829$ & -.051 & 54 & .960 \\
\hline L & $62.19 \pm 9.030$ & $61.69 \pm 7.920$ & -.219 & 54 & .828 \\
\hline K & $47.63 \pm 8.723$ & $44.90 \pm 8.126$ & -1.214 & 54 & .230 \\
\hline $\mathbf{S}$ & $47.22 \pm 6.919$ & $46.03 \pm 6.759$ & -.650 & 54 & .519 \\
\hline
\end{tabular}

$\mathrm{p}<.05^{*}, \mathrm{p}<.01^{* *}, \mathrm{p}<.001^{* * *}$ 
Table-3 : Evaluation of individuals on clinical scales $(\mathrm{N}=56)$

\begin{tabular}{|c|c|c|c|c|c|}
\hline \multicolumn{6}{|c|}{ Mean \pm SD } \\
\hline & $\begin{array}{l}\text { Experimental } \\
\quad(n=27)\end{array}$ & Control $(n=29)$ & $\mathbf{t}$ & df & $\mathbf{P}$ \\
\hline HS & $7356 \pm 7.939$ & $55.07 \pm 8.594$ & -8.344 & 54 & $.000^{* * *}$ \\
\hline D & $76.44 \pm 7.939$ & $60.45 \pm 8.403$ & -7.74 & 54 & $.000^{* * *}$ \\
\hline Hy & $61.67 \pm 12.108$ & $47.69 \pm 10.952$ & -4.536 & 54 & $.000^{* * *}$ \\
\hline Pd & $57.67 \pm 5.407$ & $49.55 \pm 7.679$ & -4.541 & 54 & $.000^{* * *}$ \\
\hline Mf & $58.96 \pm 12.675$ & $64.17 \pm 12.851$ & 1.526 & 54 & .133 \\
\hline $\mathbf{P a}$ & $54.81 \pm 10.455$ & $45.62 \pm 8.466$ & -3.628 & 54 & $.001^{* *}$ \\
\hline $\mathbf{P t}$ & $64.11 \pm 11.477$ & $57.34 \pm 7.784$ & -2.598 & 54 & $.012^{*}$ \\
\hline Sc & $62.63 \pm 7.525$ & $58.83 \pm 5.995$ & -2.099 & 54 & $.041^{*}$ \\
\hline Ma & $51.67 \pm 8.390$ & $51.69 \pm 6.188$ & .012 & 54 & .991 \\
\hline Si & $64.26 \pm 5.972$ & $62.24 \pm 5.968$ & -1.264 & 54 & .212 \\
\hline
\end{tabular}

$\mathrm{p}<.05^{*}, \mathrm{p}<.01^{* *}, \mathrm{p}<.001^{* * *}$

There has been no significant difference in the following scales masculinity-feminity (Mf), hypomania (Ma) and social introversion (Si). Yet another finding states that the scales like paranoia and psychopathic deviate that have been found to be elevated have been so only in comparison to the normal group, and despite elevation intheir $\mathrm{t}$-scores have been below 65 that show that it does not qualify to be called significant. Below are the graphical representations of the number of cases scoring and falling in the following $\mathrm{t}$ scores ranges( Figure 1,2,3,4)

\section{DISCUSSION}

The aim of our study was to assess and compare the individuals, both, having migraine diagnosed from the ICHD II criterion and the normal controls, using the MMPI-2. The results have conformed the previous researches and have been discussed under the following heads :

\section{Conversion Profile :}

Considering the potential of personality patterns to determine the evolution of migraine, conversion profile is a common finding (Ellertsen \& Klove, 1987) that became more pronounced 
Figure 1

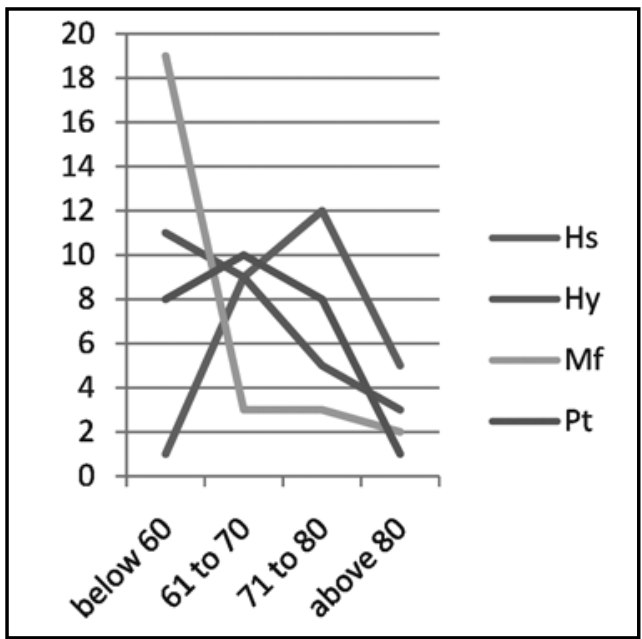

Hs- hypochondriasis, Hy- hysteria, D- depression

Figure 3

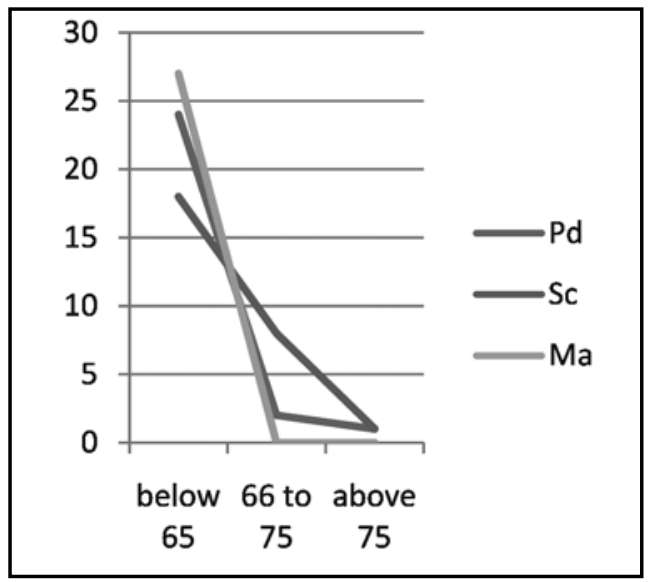

Figure 2

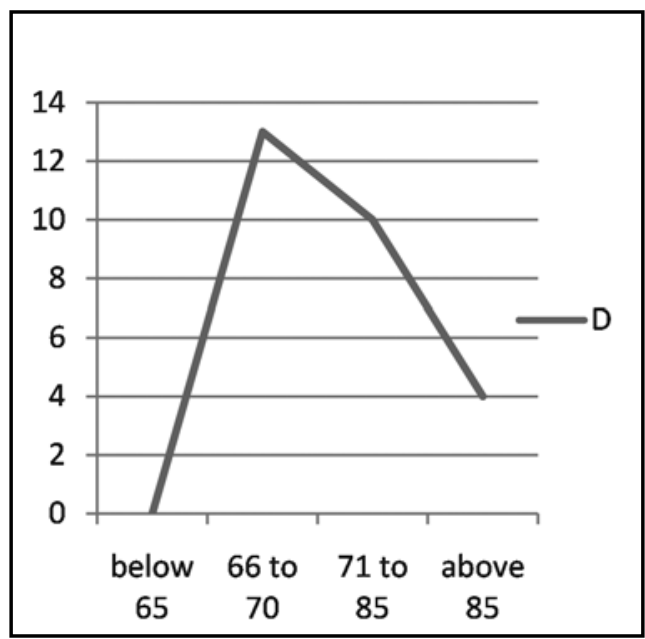

Mf- masculinity-feminity,

Pt - psychasthenia

Figure 4

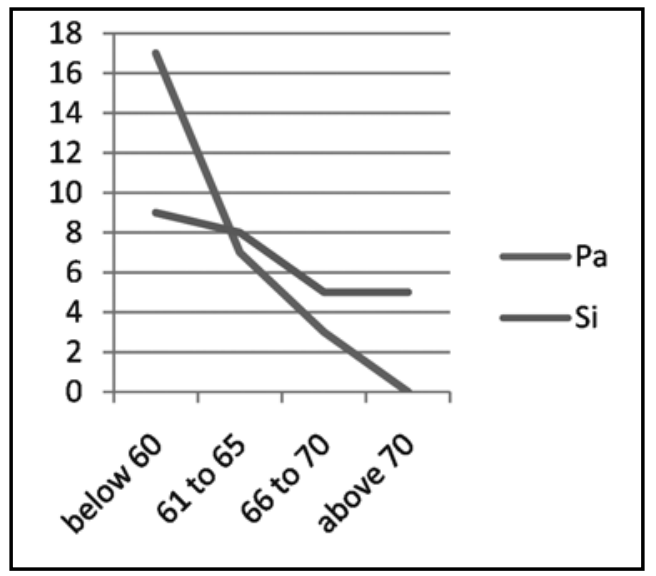

Pd- psychopathic deviate, Sc- schizophrenia, Ma- hypomania, Pa- paranoia, Si-social introversion.

or neurotic or emotionally overwhelmed with the evolution of an episodic into a chronic form of migraine. Yet it remains to be determined whether there is a direct relationship between the two events, in other words, whether such a personality style predisposes aperson or it reflects a hand of the precipitating stressors alone. In our study a notable difference exists in the values of clinical scales in the two groups which confirm the findings of earlier studies that there remains an inevitable somatic concern among the patients with migraine. The experimental group has shown a definite elevation in the three scales namely hypochondriasis, depression and hysteria.

\section{Neurotic triad and Psychasthenia :}

Considering that episodic migraine and tension 


\section{Shivani, et al.: MMPI Profile of Individuals with Migraine}

type headache are characterized, to a certain extent, by different personality profiles (Kudrow \& Sutkus, 1979), the MMPI scores of the "neurotic triad" (Hs, D, Hy) were seen more elevated in tension-type headache patients. The chronicity seemed to correlate with the emergence of psychological traits, corroborated with the results of a prior study performed on chronic daily headache patients (Mongini et al., 1994). Similar findings have appeared in our study too where the anxiety features are displayed by the psychasthenia scale, involving traits like being jumpy, always on the high strung, being very persistent and harm avoidant. In one of the studies, a more elevated muscle tenderness in the head, and even more in the neck, was observed in patients with episodic migraine characterized by anxiety or depression or both, and was supposed to be one of the mechanisms by which psychiatric disorders may affect the history of migraine, facilitating the evolution into the chronic form (Mongini et al., 2004). A recent review underlined that the frequency of depression and anxiety disorders in migraine sufferers is greater than that expected by chance association (Scher et al., 2005).

\section{Elevation of psychotic scales in headache :}

Along with this, our study has shown elevations in scales like schizophrenia, psychopathic deviate and paranoia which is unlikely, for this reason a within group severity analysis was done where it brought to notice that these scales were elevated though but only in comparison to the normal group as on analysis it was found that despite a raise, the scores were below the cut off 65 . The probable reason behind this finding could be that the patients taking the test had visited the hospital in the acute symptomatic condition, which might have led them to endorse the items related to these scales. High scores on the psychotic scales ( $\mathrm{Pa}, \mathrm{Pt}, \mathrm{Sc}$ and BIZ) too have been mentioned in earlier studies (Bigal et al., 2003). Cao and colleagues (2002) found that headache patients showed traits of neuroticismanxiety and depression, but that no abnormal personality traits were present in migraineurs with/without aura. The mechanisms linking psychiatric disorders to the natural history of migraine remain controversial.

\section{Probable explanations, and prophylactic role of MMPI :}

The discussion may be based on certain other aspects such as the reason for such a personality pattern, or if this profile could by any chance play a prophylactic role and bring about a change in the future MMPI profiles of the same patients. The changes or the comorbidity could have been a result of chronic course or overuse of the prescribed drugs or even because of the psychological theory of "learned helplessness" proposed by Seligman where it is defined as the psychological state of an individual that goes on when events are not under control (Selingman, 1975). Since psychological comorbity is quite common with individuals with migraine, it can be rightly said that comorbid disorders can influence the course, prognosis, treatment and the outcome of the illness and vice-aversa (Breslau \& Davis, 1993). There have been evidences of the involvement of the stressful situations in making the person vulnerable and even intensifying the duration, and maintenance of the headache (D'Amico et al., 2000).

\section{CONCLUSION}

We would like to end the presentation of the study by stating that the MMPI as a tool is good enough to give elaborate and meticulous information regarding the psychological and the psychopathological issues in the personality of an individual. It can hence be rightly followed that a conversion profile is evident with the elevation in hypochondriasis and hysteria scale. There exists a positive correlation in headache and depression and anxiety as displayed by raised psychasthenia scale. Along with this scales like schizophrenia, psychopathic deviate and paranoia might have been raised in some profiles perhaps 


\section{Shivani, et al.: MMPI Profile of Individuals with Migraine}

because the acute headache at the time of taking the test, but not necessarily portraying a psychotic picture

The present data and findings may be taken as baseline assessment and may be used for future researches, and possibly on larger samples to consolidate the current findings and thereby rendering an early intervention and therapeutic help for a better living.

\section{REFERENCES}

Bigal, M. E., Sheftell, F. D., Rapaport, A. M., et al. (2003) MMPI personality profiles in patients with primary chronic headache : A casecontrol study. Neurological Sciences, 24 : 103-110

Breslau, N., \& Davis, G. C. (1993) Migraine, physical health and psychiatric disorder : a prospective epidemiologic study in young adults. Journal of Psychiatric Research, 27 : 211-221.

Butcher, J. N., Dahlstrom, W. G., Graham, J. R. et al. (1989). MMPI-2. Minneapolis, MN : Minnesota University Press.

Cao, M., Zhang, S., Wang, K., et al. (2002) Personality traits in migraine and tension-type headaches : A five factors model study. Psychopathology, 35 : 254-258.

D’Amico, D., Libro, G., Prudenzano, M. P. et al. (2000) Stress and chronic headache. Journal of Headache and Pain, 1 : 49-52.

Ellertsen, B., \& Klove, H. (1987) MMPI patterns in chronic muscle pain, tension headache, and migraine. Cephalalgia, 7 : 65-71.

Goldberg, D., \& William, P. (1998) A user's guide to the general health questionnaire. Windsor, UK : NFER-Nelson.
Guidetti, V., \& Galli, F. (2002) Psychiatric comorbidity in chronic daily headache : Pathophysiology, etiology and diagnosis. Current Pain and Headache Reports, 6 : 492-497.

Headache Classification. Subcommittee of the International Headache Society (2004) The International classification of headache disorders II Ed. Cephalalgia, 24 : 9-160.

Kudrow, L., \& Sutkus, B. J. (1979) MMPI pattern specificity in primary headache disorders. Headache, 19 : 18-24.

Merikangas, K. R., Angst, J., \& Isler, H. (1990) Migraine and psychopathology. Results of the Zurich cohort study of young adults. Archives of General Psychiatry, 47 : 849-853.

Mongini, F., Ciccone, G., Deregibus, A. et al. (2004) Muscle tenderness in different headache types and its relation to anxiety and depression. Pain, 112 : 58-63.

Mongini, F., Defilippi, N., \& Negro, C. (1997) Chronic daily headache.A clinical and psychological profile before and after treatment. Headache, $37: 83-87$.

Mongini, F., Ibertis, F., \& Ferla, E. (1994) Personality characteristics before and after treatment of different head pain syndromes. Cephalalgia, 14 : 368-373.

Olesen, J., Tfelt-Hansen, P., \&Welch, K. M. A. (2000) The headaches. 2nd ed. Philadelphia: Lippincott Williams \& Wilkins.

Scher, A. I., Bigal, E. M., \&Lipton, R. B. (2005) Comorbidity of migraine. Current Opinionin Neurology, 18 : 305-310.

Selingman, M. E. P. (1975) Helplessness : on depression, development and death. WH Freeman, San Francisco.

Zwart, J. A., Dyb, G., Hagen, K., et al. (2003) Depression and anxiety disorders associated with headache frequency. The Nord-Trondelag Health Study. European Journal of Neurology, 10 : 147-152. 